\title{
Dissertation titles in EFL and UK-based contexts: How much do they differ?
}

Les titres de mémoires universitaires dans des contextes d'anglais langue étrangère et au Royaume-Uni : quelles différences?

\section{Doudja Slougui}

\section{(2) OpenEdition}

\section{Journals}

Electronic version

URL: http://journals.openedition.org/asp/5466

DOI: $10.4000 / a s p .5466$

ISSN: 2108-6354

\section{Publisher}

Groupe d'étude et de recherche en anglais de spécialité

\section{Printed version}

Date of publication: 1 November 2018

Number of pages: 135-161

ISSN: 1246-8185

\section{Electronic reference}

Doudja Slougui, « Dissertation titles in EFL and UK-based contexts: How much do they differ? », ASp [Online], 74 | 2018, Online since 01 November 2019, connection on 01 November 2020. URL : http:// journals.openedition.org/asp/5466; DOI : https://doi.org/10.4000/asp.5466

This text was automatically generated on 1 November 2020.

Tous droits réservés 


\title{
Dissertation titles in EFL and UK- based contexts: How much do they differ?
}

\author{
Les titres de mémoires universitaires dans des contextes d'anglais langue \\ étrangère et au Royaume-Uni : quelles différences?
}

Doudja Slougui

\section{Introduction}

1 The title is certainly the very first thing that readers look at when browsing library shelves or doing a computer-based search. Though it uses a few words, a good title provides a holistic picture of the contents in concise but explanatory terms. It informs about the overall work, i.e. the topic, the scope and invites the reader to go further. A poorly formulated title, however, can be confusing. If it does not accurately reflect what the content is about, or if it does not align with the topic under investigation, it can be misleading. A misleading title may give rise to expectations that cannot be fulfilled in the content, leading the reader to lose trust. Formulating a good dissertation title is, therefore, both an important and a critical issue.

2 For many student writers, wording a dissertation title effectively can be very challenging. In this regard, Swales (1990: 222) noted that "composing the few words of a title can take up an inordinate amount of time, discussion and mental effort." Title design might be a complicated process for some writers, particularly for non-native speaker (NNS) novice researchers. "These students often have difficulty in meeting the demands of the kind of writing required of them at this particular level. They are unaware of the level of preparation writing a thesis or a dissertation requires of them" (Paltridge 1997: 62). It might not come as a surprise that Anthony (2001: 192) attributes inaccurate titles to NNS. He notes that "Non-native speaker authors may be using a less effective title structure." This difficulty arises from the fact that title construction is constrained by both disciplinary and generic norms. Students, who rarely get input on 
phrasing titles in their courses, are often unaware of these rules. Additionally, Anthony observes, "in the literature that is available, there is little indication about what writing styles are appropriate in different fields and disciplines" (2001: 187). Even when some guidance is provided, he explains, "There is a confusion surrounding what is standard practice and what is good practice."

The global aim of this paper is to explore this less studied area. The purpose is to investigate the distinctive features that dissertation ${ }^{1}$ titles display in two different academic contexts: an English-speaking (UK-based context) and a non-English speaking one, where English is a foreign language (EFL context), to determine whether titles in English exhibit the same or different patterns. Therefore, the following questions will be discussed:

$4 \quad$ 1. How much does title design differ from one context to another?

5 2. What are the distinctive features that characterize dissertation titles in each context?

6 3. Is there any relationship between title design and the context where dissertations are written?

\section{Dissertation titles: A neglected aspect of genre- based studies}

7 While research on the textual features of academic genres has flourished over the last three decades (research articles, research reviews, abstracts, textbooks, dissertations...), as shown in the extensive review by Biber and Conrad (2012), investigations on dissertation titles are rather rare. Our literature search on this topic reveals that existing studies have largely focused on one particular genre: the research article. The exception is Dudley Evans (1984) whose work on Master's dissertation titles in English for Specific Purposes (ESP) can be considered as pioneering.

8 Genre-based studies on RAs have largely investigated the rhetorical sections as abstract, introduction, methods, discussion and conclusion, but titles have not received the same attention. For Swales (op. cit.), they constitute an aspect in academic genres which has been "little considered". It is only recently that interest in the textual features that typify the RA title began to emerge (Anthony 2001; Cheng et al. 2012; Gesuato, 2008; Haggan 2004; Jalilifar 2010; Moattarian \& Alibabaee 2015; Nagano 2015; Shahidipour \& Alibabaee 2017; Soler 2007). Tackling the issue from different angles, these studies consistently indicate the existence of disciplinary and generic conventions that influence the writing of titles. Elaborating on this issue, Adamzik said the following ${ }^{2}$

[...] conventions and norms employed in academic discourse vary across disciplines, periods, cultures and linguistic communities to which they belong. (1998: 31-32; my translation)

In a cross-disciplinary study, Nagano (2015: 133) attempted to identify the conventions that shape RA title design in eight disciplines. Her study pointed to disciplinary preferences for different features as well as variation within them. She argues that “... just as disciplinary conventions place constraints on, for example, the moves and language use of abstracts and introductions, they also provide a set of options for title design". Following the same line of thought, Soler (2007) has examined the recurrent 
syntactic constructions in two different genres, namely research papers and review papers in the fields of biological sciences and social sciences. She concluded that even though titles resort to the same construction across disciplines, their design shows both generic and disciplinary peculiarities.

Moattarian and Alibabaee (2015) also brought up the issue of similarity and difference in title syntactic structure. They argue that not only researchers have some preferences in the structure of titles, but some structures may also be more suitable for a specific discipline. In a more recent study, Shahidipour and Alibabaee (2017) confirmed that titles generally bear similarities in structure but maintained that differences are cross linguistic and cross-disciplinary." They explained that the differences are found in title components, title length and style.

11 Haggan pointed out that very distinguishing differences in features in the title design reflect "...fundamental differences in pragmatic intention inherent in the disciplines" (2004: 293). She added that whereas "the science title is an up-front and straight forward presentation of information...the literature title sets out to attract the reader through a kind of enigmatic hints..." (2004: 313). Between the two extremes are the linguistics titles, the structure of which is nearer to the science pattern than to the literature one.

On the diachronic dimension of titles, Salager-Meyer and Ariza (2013) investigated a corpus of 180 medical case report titles to determine whether their features - length, grammatical and syntactic complexity, and their authorship practices - change over time. Their results showed significant shifts in all features except for the nominal structure, which remained constant. This finding led the authors to conclude that the nominal pattern is distinctive of case reports unlike the verbal pattern characteristic of RAs in medicine.

Anthony attempted to clarify the confusion between 'good' and 'standard' practice. He states that, while it seems difficult to define what 'good practice' is, 'standard practice' may best be described as "that type of titles acceptable for publication" in the IEEE TRANSACTIONS journals (2001: 188). He provided an empirical description of the features that characterize RA titles in the various disciplines of computer science. His study paved the way to subsequent cross-disciplinary and discipline specific investigations, which elaborated on his analytical model. Restricting their study to RA titles in applied linguistics, Cheng et al. (2012) also examined the syntactic structures and functions of RAs in prestigious journals. The findings revealed that researchers use a variety of structures, but the most common ones are determined by disciplinary preferences.

Whereas all these studies have compared RA titles across disciplines, Afful focused on conference paper titles in applied linguistics. Three features were investigated: title length, syntactic structure and lexicon. His findings indicated that the average title length is 10.4 words, titles tended to be nominal and lexical items comprising four main categories of lexicon (domain-specific words, research-related words, verbal expressions, and country/local references). He concluded, "These lexical forms can be said to form part of the 'house style' of Applied Linguistics as a disciplinary community" (2017: 23).

Closest to the present study are Jalilifar (2010) and Gesuato (2008), who have investigated dissertation title features per se. Jalilifar compared the distinctive features 
of titles, namely theses and RAs, exclusively in applied linguistics. The selection included good quality MA and PhD titles written by Iranian students in the most prestigious universities of the country. Gesuato, on the other hand, performed a crossgeneric study of journal articles, books, conference proceedings and dissertations in linguistics. Each set comprises 250 titles, obtained from MLA bibliography by using online queries. Various features were investigated. The analysis revealed similarities and differences among titles in linguistics across publication categories, but similarities outweigh the differences. The similarities were attributed to "the titles' common genre and discipline membership, linguistic encoding, and communicative goals" (2008: 153).

The findings of these last two studies will help our own analysis and support possible cross-reference with our own findings.

\section{Title features and their impact on readers}

17 In parallel with genre studies, researchers in scientometrics have investigated the correlation between the features of RA titles in different scientific fields and their impact on readers. The title length, for instance, has been investigated to discover whether it correlates with citation rates. The contradictory findings, however, indicated a lack of consensus among researchers. Some researchers, for example Paiva et al. (2012), found that shorter titles in science journals receive more views and citations, they suggest that they are easier to understand and more attractive to readers. Others (Habibzadeh et al. 2010 cited in Subotic \& Mukherjee 2014) concluded that longer titles in the medical field seem to be associated with a higher citation rate because they include more information. Subotic and Mukherjee's (2014) findings support the idea of shorter titles (in psychology) being more effective, that is, their articles receive more citations, but the authors argue that the effect was attributed to the journal impact rather than to the title length.

Type of titles is another feature that was found to correlate positively with citation. Three types of titles were analysed in Jamali and Nikzad, 2011: descriptive titles that announce what a title is about, declarative titles that anticipate the results of the research and question titles that raise queries about the research. The authors found that even though the number of RA with interrogative titles has increased over time, the papers received more downloads but fewer citations in comparison with the other types. These findings corroborated Ball's (2009) large-scale study on RAs. His results confirmed that titles with questions showed a considerable increase over time, but the conclusions pointed at their 'marketing trick'. Readers clearly find them more appealing and more attractive, but their appeal did not guarantee later citation.

Furthermore, compound titles are among the features that received attention from information scientists. A compound title is a two-part title, most usually divided by a colon (Hartley 2007). The first part introduces the topic, and the second offers more specific information. He found that the use of colons in arts and social science titles was greater than in science. His study revealed that titles with colons were longer and more informative than those without. He concluded that even though 'colonic titles' are preferred by authors in the researched disciplines, this had no effect on the citation rates.

Wang and Bai (2007) investigated an additional feature, the syntactic structure of titles. Looking at 417 RAs, published in medical journals over a three-year period, they found 
that nominal groups were widely used in $99 \%$ of titles. Cianflone (2010: 6-7) believes that the nominal construction in the medical field "allows researchers to present their results synoptically and with an impersonal tone that is in line with the unemotional style of research papers in the medical domain." He explained that this reason made the syntactic construction popular among researchers.

Finally, reviewing title characteristics of the most cited and the least cited articles in medical journals, Jacques and Sebire (2009) offered a synoptic view. They found that the length of the title, the presence of a colon and an acronym in the title are positively correlated with the number of citations while the reference to a specific country in the title is negatively correlated with the number of citations.

This review of the literature shows that despite their different perspectives, these studies have supported and developed each other. Genre-based research attempts to bring out the linguistic variability that characterise titles in disciplines. Scientometrics depict the features of titles that influence readers. However, while focusing on published papers (research papers, review papers, case reports...) these studies have neglected other genres. Hence, the need for original research in unexplored areas.

Unlike previous studies, the choice of dissertation titles in this study grew out of a pedagogical need. First, the accuracy of titles is one of the recurrent issues which examination board members often raise when assessing students' dissertations. Second, titles in previous dissertations often serve as a model for novice research writers to formulate new ones. Third, dissertation titles written by NNS students is an under-researched area. Analysing learners' data offers many advantages, which Gilquin et al. (2007: 320) describe in the quote below:

Learner corpora, that is corpora containing data produced by L2 learners-both foreign and second language learners-are seldom analysed, which is regrettable as they hold tremendous potential for EAP studies. L2 learners admittedly share a number of difficulties with novice native writers but they have also been proven to have their own distinctive problems, which a careful corpus-based investigation can help uncover.

\section{Corpus}

The corpus consists of two sets of data, derived from the dissertation titles formulated by students on Masters Programmes in ELT (English Language Teaching) and applied linguistics. The UK-based context set comprises 91 titles extracted from the British Council Masters Dissertation Award with Best Potential for Impact on ELT between 2012 and 2017. ${ }^{3}$ It should be noted that dissertation authors in UK universities include both native and non-native English speakers.

The second set consists of 85 titles, ${ }^{4}$ selected randomly from dissertations submitted to the EFL departments in two higher education institutions in Algeria: ${ }^{5}$ The Teacher Training College, commonly known as ENSC (Ecole Normale Supérieure de Constantine) and the University of Constantine, also called Université des Frères Mentouri, between 2009 and 2017. Data are presented in Table 1.

The dissertations in the UK-based context were judged as high quality research by their respective universities and by experts from the British Council. Their titles can therefore be considered reflecting recommended practices. The second set is a random 
sample. It is assumed to represent the inaccuracies that students in non-English speaking contexts are likely to produce in wording dissertation titles.

Table 1: Basic statistics

\begin{tabular}{|l|l|l|l|l|l|l|l|}
\hline \multicolumn{7}{|l|}{ UK-based context } & \multicolumn{4}{l}{ EFL context } \\
\hline year & N titles & N words & mean & year & N titles & N words & mean \\
\hline $2016 / 17$ & 23 & 385 & 16.73 & $2016 / 2017$ & 12 & 289 & 24.08 \\
\hline $2015 / 16$ & 23 & 364 & 15.82 & $2015 / 2016$ & 19 & 379 & 19.94 \\
\hline $2014 / 15$ & 18 & 249 & 13.83 & $2011 / 2012$ & 25 & 435 & 17.40 \\
\hline $2013 / 14$ & 8 & 142 & 17.75 & $2010 / 2011$ & 10 & 172 & 17.02 \\
\hline $2012 / 13$ & 19 & 319 & 16.78 & $2009 / 2010$ & 19 & 329 & 17.31 \\
\hline TOTAL & 91 & 1459 & 16.03 & TOTAL & 85 & 1604 & 18.87 \\
\hline
\end{tabular}

\section{Methods}

After the selection of the corpus, quantitative and qualitative analyses were performed. The investigated features are the characteristics of titles. These include title length, title type, title structure, and title combinations. First, the length of titles was measured in number of words. For each title, a count of words was carried out using Microsoft Word (acronyms and hyphenated compounds were considered as a single word). Then, a $t$-test was performed to determine whether the two sets of data were significantly different from each other.

Second, the titles were classified into three categories: single-unit, two-unit and multiunit types, using punctuation (colon, semicolon, full stop, question mark and dash) as a dividing marker between units.

The internal structure of each unit was then analysed and classified according to its syntactic pattern. Four patterns were identified: Nominal phrase (Np), Verbal phrase $(\mathrm{Vp})$, Prepositional (Pp), and Full sentence (Fs).

Fourth, compound titles were examined to determine their rhetorical combinations. The scheme used by Cheng et al. (2012) was adapted to the present data. Some categories did not match the data, so they were omitted (Question: Method-Source, Question: Method, Metaphor: Question, Metaphor: Topic, Name: Topic), and others were added such as (Topic: Scope-Source; Rhetorical devices: Topic). A chi-square test was used to determine whether there was a significant difference between the frequencies in the different categories.

31 Finally, a cross-referenced analysis of the data was conducted and a conclusion was drawn. Examples from the corpus are italicized and sequentially numbered. 


\section{Results}

\subsection{Title length}

32 The analysis of both sets suggest that titles varied in length in the two contexts. "Titles fulfil their communicative aims with different word counts" (Cianflone 2010: 3). The shortest and the longest titles came from the UK-based context, indicating that some titles could be written in fewer words (Example 1); others are expressed in more words (Example 2). Similarly, in the EFL context, titles were short at times and long at others, as illustrated below (Examples 3 and 4 ):

(1) Perceptions of Fluency (3 words)

(2) 'She teaches ill, who teaches all' - Assessing the Effects of a Discovery-based Language Awareness Approach on Learners Aged 16 to 17 at an Austrian Upper-level Secondary Academic School (Gymnasium) Through the Use of Popular Sitcoms (37 words)

(3) Self-repair of Oral Production in the Classroom (7 words)

(4) A Descriptive and Analytical Study of the Communicative Functions and the Pragmatic Force of the Exclamatory Sentences in Written Discourse: A Speech Acts Perspective. The Case of 3rd Years. University of Mentouri 1 (33 words)

Table 1 summarizes the statistical data for all the investigated dissertations. The findings show the titles in the EFL context were longer than those in the UK-based context. Whereas the average title length in the EFL context was about 19 words (18.87), the average length of dissertation titles in the UK-based context was approximately 16 words (16.03). The t-test suggests that the result is significant at $p<$ $0.05(t$-value $=2.12$ and $p$-value $=0.02)$.

Although average length analysis indicates the trends, it seems difficult to interpret, as it does not reveal variation in title length. Distribution by group of words would be more appropriate in this case.

A comparison of word distribution in the two sets of data (Figure 1) shows that there were not many short titles. The titles that contained ten words and less represent $8.23 \%$ in the EFL context and $8.79 \%$ in the UK-based one. Unlike research paper titles in linguistics, which are found to be short, with an average length of 7.98 words (Soler 2007); short titles, in this study, appeared only occasionally, respectively seven and eight times in the whole corpus. However long titles, containing 21 words and more, were twice as frequent in the EFL context (32.94\%) as in the UK-based context (15.38\%). Between the two extremes lie the average length titles. Their greatest number, as clearly shown in Figure 1, ranged between 11 and 20 words in both contexts. Average length titles were more typical in the UK-based context. The titles containing between 11 and 15 words ranked first (40.65\%). This result is in agreement with the findings of Jalilifar (2010) who asserted that an average length title in applied linguistics theses approximates (14.09) words. These findings are also consistent with those obtained by Gesuato (2008), who found that dissertation titles recorded the highest number of words (12.9) as compared to other academic genres. Thus, it might be safe to conclude that UK-based dissertations have a normative, average length of title while dissertations in the EFL context are rather characterized by longer titles.

Figure 1: Title length distribution by group of words 


\subsection{Title types}

A comparison of dissertation title types in UK-based and EFL contexts (Table 4) revealed that dissertation writers in both settings seemed equally likely to use different patterns. One can observe that writers in UK universities preferred the use of singleunit titles, unlike their counterparts in EFL contexts, who tended to favour compoundunit constructions. In the UK-based context, more than half of titles were single units (57.14\%) while (41.75\%) were two units. On the other hand, in the EFL context, writers tended to opt more for compound constructions (50.58\%), as compared to single-unit titles (38.82\%). The use of multi-unit titles seemed to be unpopular in the UK-based context (1.09\%) as compared to the EFL context (10.58).

Table 4: Dissertation Title Types in UK-based and EFL Contexts

\begin{tabular}{|l|l|l|l|l|l|l|l|}
\hline & \multicolumn{3}{|l|}{ Single units } & \multicolumn{3}{|l|}{ Two units } & \multicolumn{3}{|l|}{ Multi units } & TOTALS \\
\hline & $\mathrm{N}$ & $\%$ & $\mathrm{~N}$ & $\%$ & $\mathrm{~N}$ & $\%$ & \\
\hline UK-based context & 52 & 57.14 & 38 & 41.75 & 1 & 1.09 & 91 \\
\hline EFL context & 33 & 38.82 & 43 & 50.58 & 9 & 10.58 & 85 \\
\hline
\end{tabular}

While our findings in the UK-based context seem consistent with previous research, they appeared to be different in the EFL context. Jalilifar (2010) indicated that singleunit titles (nominal phrases) are distinctive of thesis titles whereas compound-unit titles are a characteristic feature of RA in Applied Linguistics. In a similar way, Gesuato (2008) observed that single and compound units are fairly equally distributed across the genres, but in dissertations, single-unit titles are slightly higher, representing $51.2 \%$ compared to two-unit titles accounting for $48.0 \%$.

The chi-square test indicates that the result is statistically significant at $p<0.05$ (chisquare $=10.76$ and $p$-value $=0.004$ ). Therefore, we may deduce that there is a tendency for authors in each context to prefer the use of a particular type of construction: for the UK-based titles the single units and for the EFL context the compound ones.

\subsection{Syntactic structure in dissertation titles}

Additionally, a comparison of the internal structure of units revealed that the nominal and the verbal constructions were the most frequently used grammatical structures in both contexts. In the different type of titles, the internal structure of units consists of an opening phrase (mostly, nominal or verbal), which is followed by a series of prepositional phrases. ${ }^{6}$ For example, if we look at Example 5, we find that it is made up of an opening noun phrase (A Qualitative Study) that is modified by a series of prepositional phrases. As the number and type of modifying phrases vary from one title to the next, we opt for a classification, or rather a labelling that is based on the opening phrase.

(5) [A Qualitative Study] [into the Role] [of Initial Teacher Training Courses] [in the Professional Development][of Experienced Non-Native Speaker Teachers] [of English] 
The results are shown in Table 5. In the UK-based context, the nominal phrase ranked first (69.23\%) followed by the verbal phrase (24.17\%). The same ranking was also found in the EFL context where nominal phrases (77.64\%) outnumbered verbal phrases, which ranked second (21.17\%). The four examples below show the similarity between the two sets in their internal structures.

(6) The Effect of Teacher versus Peer Corrective Feedback on Spoken English Comprehensibility of Vietnamese Military Officers (UK-Nominal)

(7) Examining the Segmental and Suprasegmental Correlates of the IELTS Pronunciation Scale (UK-Verbal)

(8) The Effects of Language Aptitude and Multiple Intelligences on Language Learning Proficiency (EFL-Nominal)

(9) Enhancing EFL Learners' Sociolinguistic Competence through Culture Based Activities: The Case of Third-Year Students of English at Khenchela University (EFLVerbal)

Table 5: Syntactic Structures in Dissertation Titles

\begin{tabular}{|l|l|l|l|l|l|l|l|l|l|l|}
\hline & \multicolumn{2}{|l|}{ nominal phrase } & \multicolumn{2}{|l|}{ verbal phrase } & \multicolumn{3}{|l|}{ modifying phrases } & \multicolumn{2}{|c|}{ full sentence } & TOTAL \\
& N & $\%$ & N & $\%$ & N & $\%$ & N & $\%$ & \\
\hline UK-based context & 63 & 69.23 & 22 & 24.17 & 3 & 03.29 & 3 & 03.29 & 91 \\
\hline EFL context & 66 & 77.64 & 18 & 21.17 & 1 & 01.17 & 0 & 00 & 85 \\
\hline
\end{tabular}

In the two datasets, the prevailing patterns are $\mathrm{Np}+\mathrm{Pp}$ and $\mathrm{Vp}+\mathrm{Pp}$. That is, a nominal phrase or verbal phrase was often post-modified by a prepositional phrase, as shown in the previous examples. Other phrase openings were also used in the UK-based context, but their frequency was rather negligible (3.29\%). For example, a prepositional phrase, using the preposition towards was used in Title 82 (see appendix). In a similar way, in the EFL context, a prepositional phrase opening occurs only once (title 11).

Three full sentence (Fs) structure titles were used only in the UK-based context. Such a pattern can be illustrated by titles 30,80 and 89 in appendix 1 .

This result finds support in previous research on dissertations. Both Jalilifar (2010) and Dudley-Evans (1984) found that the nominal group with a head and a modifying group were the usual patterns in thesis title formation. This also matches results from Gesuato (2008) who claimed that the noun phrase stood as the most frequently used structure in dissertations recording about $86.9 \%$ of all structures.

The results of the chi-square show that the result is not significant at $p<0.05$ (chisquare $=1.42$ and $p$-value $=0.49$ ). This tells us that there is no difference between the syntactic structures of titles in both groups. Thus, it can reasonably be inferred that titles in the UK-based and EFL contexts share similar syntactic constructions with a dominance of the nominal structure.

\subsection{Title combinations in compound units}

Title combinations are closely related to title types. They determine the thematic relationship that exists between the title and the subtitle in compound structures. 
Although there is no single way of articulating this relationship, it is common practice to provide general information about the study in the front part and to share specific information in the second. The title usually carries information about the area of interest, or the topic that is tackled in the research, and the subtitle amplifies this information, providing details about the scope or the focus of the study, the research methodology, and the research sampling (source). It is noted that some but not all elements can occur at the same time. Authors should include only what they think is important. Swales and Feak (1994) offered a preliminary classification of titles, consisting of four patterns: Problem: Solution, General: Specific, Topic: Method and Major: Minor. The Problem-Solution type of compound titles "may be more commonly used in computer science than in other disciplines" (Cheng et al. 2012: 3). The other types, rather broad categories, have been expanded in subsequent studies (Anthony 2001; Cheng et al. 2012; Soler 2007) to account fully for the variety of titles found in different fields.

Table 6 shows an important variation in dissertation title combinations between UKbased and EFL contexts. UK-based dissertation writers use a greater diversity of categories to compose their titles, unlike their counterparts in the non-Englishspeaking context who display an unvaried style. The UK selection covers a wider range of categories compared with the EFL one. Our count shows eight different combinations, including both commonly and less commonly used varieties. Conversely, this range is more limited in EFL dissertations titles.

The statistical test indicates that the result is significant at $p<0.05$ (chi-square is 31.80 $p$-value is $<0.00001)$. Therefore, we may state that there is an association between the context and title combinations in compound units. We discuss the different types in turn, starting with the least to the most frequent categories in the UK-based corpus.

Table 6: Compound-unit title combinations: Comparison between UK-based and EFL contexts

\begin{tabular}{|l|l|l|l|l|}
\hline & \multicolumn{2}{|l|}{ UK-based context } & \multicolumn{2}{l|}{ FFL context } \\
\hline & N & $\%$ & N & $\%$ \\
\hline Topic: Method & 3 & 7.69 & 3 & 5.76 \\
\hline Topic: Description & 3 & 7.69 & - & - \\
\hline Topic: Question & 3 & 7.69 & - & - \\
\hline Topic: Source & 5 & 12.82 & 43 & 82.69 \\
\hline Topic: Scope-Source & 5 & 12.82 & 4 & 7.69 \\
\hline Topic: Method-Source & 5 & 12.82 & 1 & 1.92 \\
\hline Topic: Scope & 7 & 17.94 & 1 & 1.92 \\
\hline Rhetorical devices: Topic & 8 & 20.51 & - & - \\
\hline
\end{tabular}




\begin{tabular}{|l|l|l|l|l|}
\hline TOTAL & $39^{*}$ & & $52^{* *}$ & \\
\hline
\end{tabular}

* 38 two-unit and 1 multi-unit titles

**43 two-unit and 9 multi-unit titles occasionally. Only three titles, representing $5.76 \%$ of the total, stated the methodology occasionally. Only three titles, representing $5.76 \%$ of the total, stated the methodology element (Example 13), yet in all other instances, case study was used to mean the case of, indicating the source rather than the method, as illustrated by example 14 . The use of case study in the EFL titles does not accurately reflect the methodology followed in the research, raising a problem of internal consistency.

(13) The Effect of Formative Assessment Rubrics on EFL Writing Development: An Experimental Study

(14) The Influence of Extensive Reading on EFL Students' Writing Performance. A Case Study of Third Year Students at Jijel University

51 We note, however, that the component method was more often used in combination with Topic: Method-Source, representing $12.92 \%$ in the UK-based context and only 1.92\% in the EFL one. Examples are shown in title 3 in the UK-based list and title 2 in the EFL one.

Topic: Description. Another way to formulate a title in a compound unit is the Topic: Description pattern. The research concern is placed in the front part, followed by an explanation or description. In the corpus under study, this pattern stands out from other titles as it incorporates an acronym in the topic statement, and the description that follows rarely defines the acronym. The subtitle describes and expands the research concern.

However, using acronyms in academic titles is often regarded as awkward. Journal editors and the APA instruction manual, for example, oppose the use of these short forms in titles. Acronyms are thought to add complexity and cause confusion to readers. Unless they refer to known entities, such devices are not recommended in titles. Hartley (2008) warns against their usage and advises not to use them without spelling them out. Written as such, they may not mean anything to readers who are not familiar with them. 

the EFL titles; but UK-based authors have challenged the established recommendations. The pattern occurred three times in the compound titles (7.89\%). Example 15 is an instance of this type. The title opens up with a statement containing an acronym CEFR. The 'Common European Framework of Reference for languages' refers to the international scale of proficiency levels which practitioners in the field are assumed to be familiar with. The subtitle provides explanatory information, revealing what aspect of the topic the research is investigating. That is English language teachers' beliefs about working with the CEFR can-do statements:

(15) Working with CEFR can-do statements, ${ }^{7}$ An Investigation of UK English

Language Teacher Beliefs and Published Materials

Yet, example 16 is in some way intriguing as the nominal phrase 'my friend' personifies the topic. In fact, TED is an acronym that stands for Technology, Entertainment, and Design. The study investigates the effective use of listening strategies using a TED Talk listening programme.

(16) My friend TED: Implementing Effective Listening Strategies into Academic Listening Using TED Talks

Different from other titles that use acronyms to shorten the name for a new approach or to refer to a domain-specified expression, the acronym used in title 17 is not fieldspecific. LGBT stands for Lesbian, Gay, Bisexual and Transgender. Its position in the beginning of the title captures the attention, but the subtitle expands the reader's understanding.

(17) LGBT Inclusive Materials in ELT: An Investigation into Teacher and Learner Response towards Non-heteronormative Materials within a UK-based Context

Topic: Question. This pattern is very similar to the Topic: Scope, except that an interrogative statement indicating the scope of the research follows the main research concern (topic). As can be seen, the posed questions in the following examples seek to focus the study. They specify the research questions.

(18) Harnessing Linguistic Diversity in Polylingual, British-Curriculum Schools. Do

L1 Mediated Home Learning Tasks Improve Learning Outcomes for Bilingual Children? A Randomised Trial

(19) Using Moodle2.3 to Improve Perception Skills in EFL Listening: Does It Work?

(20) Pilot Cooperative Learning in Japanese Secondary School EFL Contexts: What are the Students' Perceptions?

While research questions in EFL titles are rare, interrogative statements seem to be used exclusively by UK-based authors.

Topic: Source. The component source in the Topic: Source combination refers to the population sampling, such as the participants, the context or the country from which data are collected. Unlike the UK-based authors, who moderately employed this construction (12.82\%), writers based in the EFL context predominantly used this construction (82.69\%). In the UK-based titles, either this pattern stands alone as a single unit, or it is used in combination with other components such as scope or method. Each category represents $12.82 \%$ of the total number of titles. Consider the following examples, which illustrate the various ways UK-based authors signal their research samples in titles.

(21) Teacher Experiences during the Shift in Medium of Instruction in Rwanda:

Voices From Kigali Public Schools 
(22) The Concept and Practice of Critical Thinking in Academic Writing: An Investigation of International Students' Perceptions and Writing Experiences

(23) Second Language Learner Multimodality and Linguistic Development in Naturalistic Settings: A Study of L2 Learners in the Chinese Street Market did not show any variety in style. The pattern bears a standard format throughout. The topical phrase was always followed by a subtitle that indicated the source, primarily the population sample and the context of research. This element was always signalled by the phrase the case of followed by the year and the university in which the participants study. For instance,

(24) Fostering Learner Autonomy in Writing through a Students-Directed Wall Magazine: The Case of 3rd Year students, University Constantine 1

(25) Factors Affecting the Writing Performance of Students' Creative Writing. The

Case of Third Year LMD Students of Ferhat Abbas University (Setif 3)

61 It is true that supervisors accept or suggest the Topic: Source format as used in the EFL corpus, but no university regulations require it. What is it then that makes the pattern so widespread among Algerian students? Unless qualitative studies are undertaken in the area, no answer seems to be possible and no generalisation can be made beyond the scope of this study.

Topic: Scope is one of the important types in title writing. Limiting the scope of the research is an aspect that researchers see as a requirement for a good title (Swales 1990; Swales \& Feak 1994). The purpose of indicating the scope is to distinguish a study from others in the same research area by pointing out its specific focus. In this study, Topic: Scope occurred relatively frequently in the UK-based context (18.42\%). It ranked second on the list. This pattern was used in simple statements as illustrated in example 26 , and in combination with other components in Topic: Scope-Source $(18.42 \%)$ as shown in example 27.

(26) Subtitles in Authentic Video Listening: An Exploration of the Benefits of 14 Captions in Relation to Sensory Preference Types

(27) Learning Vocabulary from Subtitled Videos: An Investigation into the Effectiveness of Using Subtitled Videos for Intentional Vocabulary Learning in Saudi Arabia

In the EFL context, the Topic: Scope pattern was rather rare. As such, it appeared only once (Example 28), but in the complex structure Topic: Scope-Source, it appeared three times (7.69\%), as shown in example 29:

(28) Evaluation of an EFL Textbook: Vocabulary Presentation and Teaching Techniques

(29) From Learning to Write to Writing to Write. Instilling Habit Formation in our Learners: Cognitive and Metacognitive Perspectives. The Case of First Year Students. University of Constantine 1

In view of these preliminary findings, it can be deduced that the scope of the research, stated in an affirmative or interrogative form has a differing importance in the two academic settings. It seemed to be valued in UK-based titles while underestimated in the EFL ones.

Rhetorical devices: Topic. Unlike other categories, this type of title is characterized by the use of a variety of devices such as metaphor, quotation, allusion, and rhetorical question. Usually regarded as literary devices, these figures of speech have carved out a place in ELT dissertation titles. While metaphors are used to compare two unrelated 
things, both quotation and allusion refer to prior knowledge. In one instance, the reference is made explicit by the use of quotation marks; in the other, the allusion may be inferred. According to Liu (2011: 708), "the primary function of metaphors in titles is to create rhetorical effect". The author explains, "The use of metaphor makes the title original and full of suspense. With the help of metaphor, readers are sure to be curious about the content and eager to know more." For Hartley (2008: 25), titles that use "allusions" fulfil "an attractive function". He, nevertheless, acknowledges that "Literary and cultural references are difficult for non-native speakers of the language to understand" and advises avoiding their use.

Totally absent from the EFL context, this type of title represents $21.05 \%$ of the UKbased corpus, i.e. the highest rank on the list. In compound titles, quotation, allusion and metaphor often stand as the main topic followed by an explanatory subtitle that clarifies the meaning in relation to the research purpose. As shown in the following examples:

(30) 'She teaches ill, who teaches all' - Assessing the Effects of a Discovery-based Language Awareness Approach on Learners Aged 16 to 17 at an Austrian Upperlevel Secondary Academic School (Gymnasium) Through the Use of Popular Sitcoms (31) Up, up and away! Taking off with SFG: An Investigation into the Impact of Selected Systemic Functional Grammar (SFG) Concepts on Students' Writing of a Film Review

(32) Invisible no more: Shedding Light on the Prejudices that Native English Speaking Caribbean Nationals Face in the TESOL Job Market

In 'She teaches ill, who teaches all...' the author quotes a proverb as a critique of the shortcomings of rule-based approaches to ELT and calls for an alternative methodology, which is more selective and caters better for young people's needs. In 'Up, up and away! ...' allusion is made to a song from the sixties that illustrates the sense of freedom flying can inspire. The study discusses the limits of traditional approaches to teaching grammar, and invites practitioners to fly in some other direction by teaching grammar through FSG. 'Invisible no more...' is also an allusion to a book ${ }^{8}$ about racial prejudice and black discrimination. The research reflects on the prejudice that NES face on the ESL job market.

Other patterns in this type of title take the form of metaphor. Example 33 compares a Japanese University to a country where part of its land is considered as 'Foreign Territory'. Here, 'Foreign Territory' alludes to the language course, known as "English Village":

(33) Foreign Territory: An Ethnographic Study of an "English Village" within a Japanese University

Example 34 is a rhetorical question. It is what Hartley (2008: 24) considers as a startling and effective opening that attracts attention. "Are You Speaking Comfortably?" addresses teachers who are the most highly exposed population to vocal dysfunctioning. For Cianflone (2010: 4), such rhetorical questions meet three communicative objectives: a) the addressed topic needs further study; b) it offers one answer to the posed question c) it awakens readers' curiosity.

(34) 'Are You Speaking Comfortably?' A Consideration of the Risk Factors, Implications and Prevention of Muscle Tension Dysphonia in teachers aimed at creating a rhetorical effect on readers. In the EFL context, no title uses such 
patterns. It might then be concluded that titles that bid for attention are distinctive of the UK-based context.

\section{Conclusion}

71 This article has attempted to gain understanding on how dissertation titles were designed in two different contexts: an English speaking and an EFL context. The aim was to identify the features that typify titles in these environments. Inferences drawn from this study could help novice writers design titles according to the standards that characterize dissertations which won and received honours for their quality. Three questions are asked: whether title design differs from one context to another, what features characterize dissertation titles in each context and if there is any relationship between title design and the context where dissertations are written.

The findings suggest that there is a clear difference between the two corpora. Distinctive features marked each context. The dominant characteristics of UK-based titles were medium length, single-unit structure and original and attractive content. Titles in the EFL context were rather long, with a complex structure and a standardized content format. Titles, nonetheless, share a common feature, which is a nominal syntactic structure.

One major reason that could account for these differences is that the students' perception of the function of titling is perceived differently in the two contexts. While a title in the UK-based dissertation fulfils the rhetorical functions of attracting besides informing; in the EFL context, the title is primarily descriptive, providing specific information on what the research is about, where it has taken place and who took part in it. Catchy phrases, appealing quotations, intriguing question titles, even a threeword title illustrated in the UK-based dissertations are all meant to spark the readers' interest, awaken their curiosity and incite them to read beyond the title. Such a risktaking strategy is rare in EFL dissertations - at least in the context under study. Unlike authors in the UK-based context who dare to try something new and be creative, Algerian student writers prefer to play safe. They value a safe title that replicates standard models rather than come up with a creative and original one that challenges established practices. At this level, EFL students hardly compete for a wider readership. Their concern is to satisfy the immediate audience, i.e. the examination board. They opt for a design that allows them to be explicit about their work. Through lengthy compound titles, they choose explicitness at the expense of conciseness and attractiveness. In this respect, Liu observed that for a great number of NNS students "The accuracy of expressions is preferred to the ideas and aesthetic feeling transmitted by words." In addition, the author deplored that students "recite some model" in their own writing. Consequently, their designs, "similar in structures to each other and lacking in originality, are full of platitude" (Lui 2011: 710).

What effect does this strategy have on readers? It appears that students in the EFL context have turned a common practice of title writing into a 'must do' design. All titles bear the same pattern. This uniformity of design and fixed structure prototype, in our opinion, have destroyed the distinctiveness and attractiveness which titles are expected to bring to their readers. Such titles are just commonplace, lacking identity and originality. About this, Fox and Burns' remark is right to the point: "titles written to focus on narrow aspects of a study - the specific geographic region or population 
studied - are less impactful than papers with titles that emphasize the broader conceptual or comparative context of a study" (2015: 1978).

Though limited in scope, this study has attempted to highlight how titles written by novices in different academic settings differ and how some common practices in EFL context take over normative standards. It is hoped that the implications derived from this research would help student writers to improve the quality of titles in their future research works, that course designers would award more attention to this neglected genre and that researchers would expand more studies in the area. To challenge their difficulties, students need to develop awareness of the generic and disciplinary norms that govern appropriate title design in their discipline. Dissertation writers are expected not only to meet accuracy requirements as textual and syntactic features, but also to achieve rhetorical variety to ensure identity and attractiveness to their work. Tutors and advisors, on the other hand, may help their apprentices with more guidance for writing text headings. In doing so, they would familiarize them with the conventions that constrain disciplines and acquaint them with the norms of appropriate usage. In other words, advisors' support to supervisees would be a customized guidance. In order to meet this aim, researchers' contribution to genrebased studies is significant. Data should not only be driven from corpus-based research on journal articles and other published material, but also from learner based-corpora. Such an approach, as Gilquin et al. (2007) posit, must be encouraged, as it has the potential of quantifying and identifying writing difficulties experienced by novice writers in academic settings where English is a foreign language. This study has attempted to do so by investigating a rather unexplored area. It is suggested that future studies would analyse larger corpora and offer more results that support the present study.

\section{BIBLIOGRAPHY}

ADAMZIK, Kirsten.1998. "Le début du texte. Le titre et les premières phrases, dans des textes académiques". Cahiers de la Linguistique Française 20, 31-64.

AffUL, Joseph Benjamin Archibald. 2017. “A linguistic analysis of conference paper titles in applied linguistics". International Journal of Foreign Language Teaching \& Research 5/18, 11-24. Retrieved from <http://jfl.iaun.ac.ir/article_54832_c70f61941e0573535fa204cc7c2322f3.pdf> on $27 / 10 / 2017$.

ANTHONY, Laurence. 2001. "Characteristic features of research article titles in computer science". IEEE Transactions on Professional Communication 44/3, 187-194. DOI: 10.1109/47.946464.

BALL, Rafael. 2009. "Scholarly communication in transition: the use of question marks in the titles of scientific articles in medicine, life sciences and physics 1966-2005". Scientometrics 79/3, 667679. DOI: 10.1007/s11192-007-1984-5.

BIBER, Douglas \& Susan CONRAD. 2012. Register, Genre and Style. Cambridge: Cambridge University Press. DOI: $10.1017 /$ CBO9780511814358. 
CHENG, Stephanie W., Chih-Wei Kuo, \& Chih-Hua Kuo. 2012. "Research article titles in applied linguistics". Journal of Academic Language \& Learning, 6/1, 1-14. Retrieved from <www.journal.aall.org.au/index.php/jall/article/download/178/125>on 8/8/2017.

CIANFLONE, Eugenio. 2010. "Scientific titles in veterinary medicine research papers". English for Specific Purposes World 9/4, 1-8. Retrieved from <http://www.esp-world.info/Articles_30/ titles\%20in\%20vet\%20med_Cianflone.pdf> on 18/3/2018.

DUDLEY-EVANS, Tony. 1984. "A preliminary investigation of the writing of dissertation titles". The ESP Classroom: Methodology, Materials, Expectations 4, 40-46. Exeter, U.K: Exeter Linguistic Studies.

Fox, Charles W. \& Sean C. BuRns. 2015. "The relationship between manuscript title structure and success: Editorial decisions and citation performance for an ecological journal". Ecology and Evolution. 5/10, 1970-1980. DOI: 10.1002/ece3.1480.

GESUATO, Sara. 2008. "Encoding of information in titles: Academic Practices across four genres in linguistics". In Taylor, C. (ed.), The Role E-corpora in Translation and Language Learning. Ecolingua: Italy: Edizioni Università di Trieste, 127-157. Retrieved from <https://www.researchgate.net/ publication/266044494> on 12/2/2018.

GILQUin, Gaëtanelle, Sylviane GRANGER \& Magali PAQUOT. 2007. "Learner corpora: The missing link in EAP pedagogy". Journal of English for Academic Purposes 6/4, 319-335. DOI: 10.1016/j.jeap. 2007.09.007.

HAGGAN, Madeline. 2004. "Research paper titles in literature, linguistics and science: dimensions of attraction”. Journal of Pragmatics 36, 293-31. DOI: 10.1016/S0378-2166(03)00090-0.

HARTLEY, James. 2007. "Planning that title: Practices and preferences for titles with colons in academic articles". Library and Information Science Research 29/4, 553-568. DOI: 10.1016/j.lisr. 2007.05.002.

HARTLEY, James. 2008. Academic Writing and Publishing: A Practical Handbook. Abingdon, UK: Routledge. DOI: 10.4324/9780203927984.

JACQUES, Thomas S. \& Neil J. SEBIRE. 2010. "The Impact of article titles on citation hits: An analysis of general and specialist medical journals". Journal of the Royal Society of Medicine (JRSM) 1/2, 1-5. DOI: $10.1258 /$ shorts.2009.100020.

JALILIFAR, Alireza. R. 2010. "Writing titles in applied linguistics: A comparative study of theses and research articles". Taiwan International ESP Journal 2/1, 27-52. Retrieved from <https:// www.researchgate.net/publication/

267416862_Writing_titles_in_applied_linguistics_A_comparative_study_of_theses_and_research_articles> on $3 / 8 / 2017$.

JAMALI, Hamid R. and Mahsa NiKZAD. 2011. "Article title type and its relation with the number of downloads and citations". Scientometrics 88/2, 653-661. DOI: 10.1007/s11192-011-0412-z.

LIU, Yan-chun. 2011. "The enlightenment of metaphors in titles on English writing teaching". Sino-US English Teaching 8/11, 706-712. Retrieved from <http://www.maraserrano.com/MS/ articulos/mt_70500674.pdf> on 28/3/2018.

MoATtARIAn, Aasa \& Ahmad ALIBABAEE. 2015. "Syntactic structures in research article titles from three different disciplines: Applied linguistics, civil engineering, and dentistry". The Journal of Teaching Language Skills (JTLS) 7/1, 27-50. DOI: 10.22099/JTLS.2015.3530.

NAGANO, Robin L. 2015. "Research article titles and disciplinary conventions: corpus study of eight disciplines”. Journal of Academic Writing 5/1, 133-144. DOI: 10.18552/joaw.v5i1.168 
Paiva, Carlos E., João Paulo da SIlveira NOGUeIRA LIMA \& Bianca SAKAMOTO RIBEIRO PAIVA. 2012.

"Articles with short titles describing the results are cited more often". Clinics 67/5, 509-513. DOI:

10.6061/clinics/2012(05)17.

PALTRIDGE, Brian. 1997. “Thesis and dissertation writing: Preparing ESL students for research".

English for Specific Purposes 16/1, 61-70.

SALAGER-MEYER, Francoise. \& Maria Angeles alCARAZ ARIZA. 2013. "Titles are "serious stuff": A historical study of academic titles". JAHR 4/7, 257-271. Retrieved from <https://hrcak.srce.hr/ file/162614> on $22 / 3 / 2018$.

SHAHIDIPOUR, Vahid \& Ahmad AliBABAEE. 2017. "Syntactic structures and rhetorical functions of electrical engineering, psychiatry, and linguistics research article titles in English and Persian: a cross-linguistic and cross-disciplinary study". Journal of Teaching Language Skills (JTLS) 36/1, 145175. DOI: $10.22099 /$ jtls.2017.4066.

SOLER, Viviana. 2007. "Writing titles in science: An exploratory study". English for Specific Purposes 26, 90-102. DOI: 10.1016/j.esp.2006.08.001.

Subotic, Sinisa \& Bhaskar Mukherjee. 2013. "Short and amusing: The relationship between title characteristics, downloads, and citations in psychology articles". Journal of Information Science 40/1, 115-124. DOI: 10.1177/0165551513511393.

SWALES, John M. 1990. Genre Analysis: English in academic and research settings. Cambridge:

Cambridge University Press. DOI: 10.1016/0889-4906(92)90009-Y.

SWALES, John M. \& Christine B. FEAK. 1994. Academic Writing for Graduate Students: A course for nonnative speakers of English. Ann Arbor: The University of Michigan Press.

WANG, Yan \& Yongquan BAI. 2007. “A corpus-based syntactic study of medical research article titles”. System 35/3, 388-399. DOI: 10.1016/j.system.2007.01.005.

\section{NOTES}

1. Dissertation in this study refers to a long piece of research writing that is done in partial fulfilment of the requirements for the degree of Master in applied linguistics.

2. [...] normes et conventions diffèrent entre les multiples discours du vaste champ que constitue l'univers académique, variant selon les disciplines, les époques, l'environnement culturel et les communautés linguistiques auxquels ils se rattachent. (1998: 31- 32)

3. See Appendix 1.

4. See Appendix 2.

5. Algeria's official language is Arabic. Recently, Berber has been recognized as a national language. French is the first foreign language. Although it continues to be widely used for educational and administrative purposes, it lost the strong position it used to have. English has a foreign status too. Though popular among young people, its uses are rather limited.

6. Very occasionally, an infinitive phrase follows the opening noun phrase. See example (Title 66) in appendix 2.

7. Capitalisation, italics and bold type appear in the original title.

8. Invisible No More: Police Violence Against Black Women and Women of Color by Andrea Ritchie 


\section{ABSTRACTS}

Formulating a dissertation title effectively is both a critical and an important issue for many students, particularly non-native speakers of English. This difficulty arises from the fact that titles are constrained by both disciplinary and generic conventions. However, despite the growing body of literature on genre-based studies, these rhetorical sections have not yet received due attention. The global aim of this paper is to compare between Master's dissertation titles written by students in an English-speaking context, the United Kingdom and a context where English is a foreign language, Algeria. In particular, this study seeks to examine the distinctive features that titles display and find out how much they differ. Four features were investigated in 176 titles: title length, title type, title structure, and title combinations. The findings suggest that, except for their internal syntactic structure, which showed no variability, titles differ in various aspects, indicating that contexts where dissertations are written might be an influential source on title design. Implications from this study will help to enlarge research in the area and develop students' awareness about title design in academic writing.

Formuler un bon titre pour un mémoire universitaire est à la fois un acte important et difficile à accomplir pour de nombreux étudiants, en particulier pour ceux dont la langue maternelle n'est pas l'anglais. Cette difficulté résulte du fait que l'écriture des titres est soumise à des règles strictes qui régissent leur emploi dans un texte. Les normes et les conventions du discours universitaire changent d'une spécialité à l'autre, et varient d'un type de document à l'autre. L'objectif de ce travail est de comparer les titres dans les travaux de recherche de Master des étudiants, préparant un diplôme d'enseignement de la langue anglaise dans des universités britanniques et dans des universités algériennes. Le but est d'identifier les caractéristiques qui distinguent les titres dans chaque contexte. Le corpus est composé de 176 titres. Quatre éléments sont analysés: longueur, type, structure et composants du titre. Les résultats montrent qu'à l'exception du la structure syntactique qui reste identique, tous les autres éléments divergent. Les conclusions de cette étude contribuent à élargir la recherche dans le domaine, et à sensibiliser les étudiants en matière de conception et de présentation des titres dans leurs travaux de recherche.

\section{INDEX}

Keywords: academic writing, dissertation title, genre analysis, title features

Mots-clés: analyse de genre, caractéristiques du titre, écrit universitaire, titre de mémoire

\section{AUTHOR}

\section{DOUDJA SLOUGUI}

Doudja Slougui is a lecturer in the Department of English at École Normale Supérieure Assia Djebar de Constantine, Algeria and former course tutor of the École Doctorale d'Anglais. She received her M.Sc. degree in TESP from the University of Aston - Birmingham, U.K. and her Doctorat d'État in applied linguistics from the University of Constantine - Algeria. Her research interests cover ESP, second language writing, NNS scholarly publication and genre analysis. dslougui@hotmail.com 